\title{
Epidemiology Characteristics and Trends of Lung Cancer Incidence in Iran
}

\author{
Zeinab Almasi ${ }^{1}$, Hamid Salehiniya ${ }^{2,3}$, Neda Amoori $^{4}$, Mostafa Enayatrad ${ }^{5 *}$
}

\begin{abstract}
Background: Lung cancer is one of the most common cancers in the world and a major cause of death from cancer. One of the important indicators to compare the prevalence and incidence of the disease is a change in the trend. The aim of this study was to investigate the changes in the incidence of lung cancer in Iran. Materials and Methods: This study was conducted based on existing data obtained from a national registry of cancer cases and the Disease Management Center of Ministry of Health in Iran. All cases registered in the country were included during 2003-2008. Incidence rates were reported based on the direct method and standard population of World Health Organization. The study also examined the morphology of common lung cancers. Trends in incidence underwent joinpoint regression analysis. Results: Based on the results of this study, 14,403 cases of lung cancer have been recorded of which 10,582 cases were in men and 3,821 in women. Highest incidence rates were observed in the 80-84 age group. Considerable variation across provinces was evident. In females squamous cell carcinoma (SCC) demonstrated a reduction from $24 \%$ to $16 \%$ of lesions over the period of study, while adenocarcinoma rose from $21 \%$ to $29 \%$. In males a similar reduction in SCC was apparent $(42 \%$ to $29 \%$, again with increase in $\mathrm{AC}(13 \%$ to $18 \%)$. Conclusions: The results show that the increase in the incidence of lung cancer the trend is that more men than women and in men and may be caused by changes in smoking pattern. The incidence of lung cancer in the North West and West provinces was higher than in other regions.
\end{abstract}

Keywords: Incidence - Iran - lung cancer - trend - histopathology - SCC - AC.

Asian Pac J Cancer Prev, 17 (2), 557-562

\section{Introduction}

Cancer is the second leading cause of death in developing countries (Ferlay et al., 2010; Keyghobadi et al., 2015; Koohi et al., 2015; ). In Iran located in epidemiologic transition, cancer is the third cause of death after coronary heart disease and accidents (Mousavi et al., 2009; Khajehkazemi et al., 2013). Incidence of cancer is increasing in developing countries as a result of population aging and cancer- associated lifestyle such as smoking, physical inactivity, obesity, stress and so on. It is expected to increase the number of new cases of cancer from 10 million per year in 2000 to 15 in 2020, and nearly $60 \%$ of them occurred in developing countries (Parkin et al., 2005).

Lung cancer is a major health problem and the leading cause of cancer deaths worldwide (Ming et al., 2014) so scholars pay more and more attention to its diagnosis, treatment and prognosis. According to the International Agency for Research on Cancer (IARC) GLOBOCAN World Cancer Report, lung cancer affects more than 1 million people a year and certainly stands to be a leading cause of cancer mortality worldwide (Jemal et al., 2011).
In females, it was the fourth most commonly diagnosed cancer and the second leading cause of cancer death (Hosseini et al., 2009). The majority of the cases now occur in the developing countries $(55 \%)$, a large increase since the estimates in 1980 , when it was estimated that only $31 \%$ of lung cancer cases occurred in developing countries (Parkin et al., 2005; Ferlay et al., 2010). As lung cancer epidemic is decreasing but in developed countries has growing trend (Siegel et al., 2013). In the United States, lung cancer is the second most common cancer in men and women, and it is the leading cause of cancerrelated death (Horner et al., 2009; Jiao et al., 2014). Study in Europe showed that most deaths due to cancer, lung cancer and the third most common cancer in both gender (Bosetti et al., 2008). Despite diagnostic and therapeutic improvements, the survival of lung cancer patients is still severe; with only $15 \%$ patients in US survive more than five years after diagnosis (Cruz et al., 2011).

Lung cancer is often divided into small cell lung cancer (SCLC) and non-small cell lung cancer (NSCLC), (includes squamous cell carcinoma (SCC), adenocarcinoma (AC) and large cell carcinoma (LCC) (Hussain et al., 2001), NSCLC accounts for approximately $85 \%$ of all cases of

${ }^{I}$ Department of Epidemiology and Biostatistics, School of Health, Zahedan University of Medical Science, ${ }^{2}$ Minimally Invasive Surgery Research Center, Iran University of Medical Sciences, ${ }^{3}$ Department of Epidemiology and Biostatistics, Tehran University of Medical Sciences, ${ }^{5}$ Department of Epidemiology, Shahid Beheshti University of Medical Sciences, Tehran, ${ }^{4}$ Health Officer, Abadan School of Medical Sciences, Abadan, Iran*For correspondence: mostafaenayatrad@gmail.com 
lung cancer (Molina et al., 2008).

Lung cancer was an occupational disease (Kabat, 1996; Chan-Yeung et al., 2003; Du et al., 1996). One of the important risk factors for lung cancer is smoking. Smokers have a 20 -fold increased risk of developing lung cancer than never-smokers, with $85 \%-90 \%$ of all lung cancers being directly linked to tobacco exposure (Hosseini et al., 2009). Smoking accounts for $80 \%$ of the worldwide lung cancer burden in males and at least $50 \%$ of the burden in females. Smoking avoidance could almost completely eliminate the disease (Kazemi-Lomedasht et al., 2013). The World Health Organization has identified Smoking use as the leading global cause of preventable death, killing almost 6 million people every year and causing huge economic damage worldwide. Most of these deaths occur in the low- and middle-income countries and this disparity is expected to widen over the coming decades (Organization, 2011). The carcinogenesis of lung cancer may result from a variety of triggers, among which tobacco consumption was indicated to be one of the primary agents. While there exists a fact that never-smoking patients account for $15 \%$ of lung cancer patients (Hadoux et al., 2011). In Asian countries about 30-40\% of lung cancers occur in never smokers, though only $10-15 \%$ of lung cancers occur in never smokers in Europe and North America (Toh and Lim, 2007). Exposure to factors such as occupational carcinogens, air pollution, and pollution from burns caused by cooking and nutrition are other risk factors for lung cancer (Fauci and Anthony, 2008). Age, gender, race, pre-existing lung disease, radon exposure, viral infection, environmental pollution, second-hand smoking and occupational exposures also are important contributors. In addition, direct evidence for a genetic predisposition to lung cancer is highlighted by several recent genome-wide association studies (GWAS) that have been done on lung cancer populations (Wang et al., 2008; Li et al., 2010; Miki et al., 2010; Hu et al., 2011; Shiraishi et al., 2012).

According to a major share lung cancer overall mortality from cancer and the amount of smoking dependence, the fact shows that lung cancer is a major health problem with the prognosis is generally bad for the world and the recognition of the status and trends of lung cancer and changes in recent years can be helpful in planning for prevention, and even predictions for supply necessary health care in the future, especially lung cancer. The aim of this study was to investigate the changes in the incidence of lung cancer.

\section{Materials and Methods}

\section{Data source}

This analytic study was done based on longitudinal program in Iran that similar to many countries in the world that have national registry of cancer (NCR) is trying to identify all cases of cancer occurring in Iran from 2003 to 2008. Data used in this study were obtained from a NCR, and Disease Control and Prevention (CDC) of Ministry of Health and Medical Education in Iran for 2003-2008 (Goya, 2007). In 2008 in Iran, there are 30 provinces and 41 Medical Universities. Deputy for the health of each university is responsible for health issues of the population and all health activities are managed by these deputies. All deputies for health have been included in the NCR. Registrar would apply the national registration software, which was developed by CDC. For pathologic centers, without software, the cancer records were gathered manually. The cancer office of CDC should provide techniques and funding supports. The data are transmitted every 3 months, by electronic file and also hard copy of "Cancer Registry Data Collection Form" this form is comprised of three parts: Part I, regarding patient's identity characteristics in addition to the name of biopsy-taker physician, name of hospital, location of which the biopsy is taken, clinical diagnosis and date of biopsy sent to histological laboratory and demographic information of the patients includes race and residence. Part II includes the most important findings of patient's clinical history. Part III includes preclinical findings. The information includes the primary location of the tumor, date of cancer diagnosis, morphology, and histology and its behavior and diagnosis method. Physicians fill the form of clinical data and the official personnel fill the identity and demographic information. Quality control has been coordinated in five main areas by cancer office of CDC: i) Regarding completeness of coverage, ii) completeness of details, iii) accuracy of data, $i v$ ) accuracy of reports, v) accuracy of interpretation, and vi) repeated cases are deleted from national data. Surveillance of pathology is based on the cancer record in several selected provinces to compare it with the present pathology cancer record for a general and complete evaluation and also for the accuracy of the collected data. IARC software provides a way to identify inaccuracies in data coding. Accordance of The International Classification of Diseases for Oncology (ICD-OC: Topography with ICD-OM: Morphology) is done manually and also by considering age and sex groups (pathology file of fatal error has been revised by the Scientific Society of Pathology of Iran and also by two masters in pathology). Method for deleting repeated cases: For the lack of any classified National Identification Numbers, the process for deleting the repeated cases was completed by a manual review of the record. After editing data of each province and considering in mind that for deleting of repeated cases, similar cases should also be the same as morphology, topography, identity, and

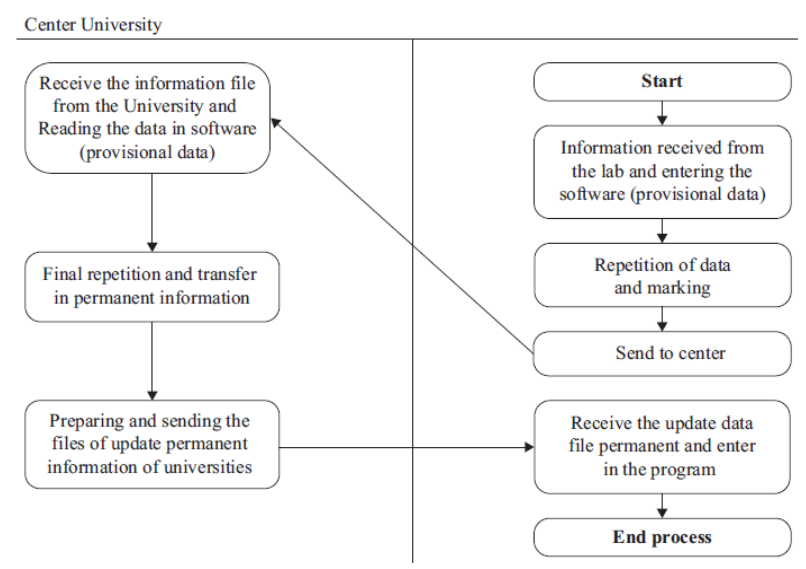

Figure 1. Process of Data Collection of Cancer Cause in Iran 
Table 1. Frequency, CIR, and ASR-based of Sex and Year

\begin{tabular}{|c|c|c|c|c|c|c|c|c|}
\hline \multirow[t]{2}{*}{ Years } & \multicolumn{2}{|c|}{ Frequency $(\%)$} & \multirow[b]{2}{*}{ Total } & \multicolumn{2}{|c|}{ CIR } & \multicolumn{2}{|c|}{ ASR } & \multirow[t]{2}{*}{ Male: Female } \\
\hline & Male & Female & & Male & $\overline{\text { Female }}$ & Male & $\overline{\text { Female }}$ & \\
\hline 2003 & 783 & 281 & $1064(2)$ & 2.56 & 1.67 & 3.2 & 1.23 & 2.78 \\
\hline 2004 & 1163 & 343 & $1506(3.30)$ & 3.35 & 1.04 & 4.38 & 1.51 & 3.39 \\
\hline 2005 & 1303 & 484 & $1787(3)$ & 3.6 & 1.41 & 4.63 & 2.04 & 2.69 \\
\hline 2006 & 1491 & 452 & $1943(3)$ & 4.14 & 1.32 & 5.35 & 1.87 & 3.29 \\
\hline 2007 & 1512 & 567 & 2079 (3) & 4.2 & 1.66 & 5.46 & 2.34 & 2.66 \\
\hline 2008 & 2211 & 839 & $3050(4)$ & 6.14 & 2.46 & 8.04 & 3.55 & 2.63 \\
\hline Total & 8463 & 2966 & 11429 & & & & & 2.86 \\
\hline
\end{tabular}

ASR=Age-standardized incidence rate, $\mathrm{CIR}=$ Crude incidence rate

Table 2. Change in ASR According to Age Group and Gender from 2003-2008

\begin{tabular}{|c|c|c|c|c|c|c|c|c|c|c|c|c|}
\hline \multicolumn{3}{|c|}{ Age-category 2003} & \multicolumn{2}{|c|}{2004} & \multicolumn{2}{|c|}{2005} & \multicolumn{2}{|c|}{2006} & \multicolumn{2}{|c|}{2007} & \multicolumn{2}{|c|}{2008} \\
\hline & Male & Female & Male & Female & Male & Female & Male & Female & Male & Female & Male & Female \\
\hline $0-4$ & 0 & 0.07 & 0 & 0 & 0 & 0.07 & 0.1 & 0 & 0 & 0 & 0 & 0 \\
\hline $5-9$ & 0 & 0.08 & 0.05 & 0 & 0.05 & 0 & 0 & 0 & 0 & 0 & 0 & 0 \\
\hline $10-14$ & 0 & 0.02 & 0.04 & 0.02 & 0 & 0.02 & 0.04 & 0 & 0 & 0 & 0.02 & 0 \\
\hline $15-19$ & 0 & 0.19 & 0.1 & 0.02 & 0.04 & 0.08 & 0.06 & 0.04 & 0 & 0.09 & 0 & 0.02 \\
\hline $20-24$ & 0.09 & 0.45 & 0.36 & 0.34 & 0.21 & 0.17 & 0.18 & 0.17 & 0.15 & 0.17 & 0.09 & 0.03 \\
\hline $25-29$ & 0.14 & 0.63 & 0.9 & 0.29 & 0.2 & 0.26 & 0.3 & 0.26 & 0.3 & 0.04 & 0.28 & 0.19 \\
\hline $30-34$ & 0.13 & 0.49 & 0.85 & 0.77 & 0.57 & 0.2 & 0.53 & 0.41 & 0.49 & 0.17 & 0.8 & 0.09 \\
\hline $35-39$ & 0.59 & 1.3 & 1.77 & 0.87 & 1.12 & 0.77 & 1.21 & 0.77 & 0.97 & 0.55 & 0.68 & 0.46 \\
\hline $40-44$ & 1.37 & 1.8 & 3.9 & 0.96 & 2.71 & 1.38 & 2.87 & 1.06 & 2.16 & 0.99 & 2.02 & 0.84 \\
\hline $45-49$ & 3.58 & 4.04 & 8.17 & 3.96 & 5.59 & 2.88 & 6.41 & 2.66 & 4.19 & 1.2 & 3.65 & 1.29 \\
\hline $50-54$ & 8.66 & 7.61 & 21.21 & 5.18 & 14.28 & 4.54 & 17.37 & 4.03 & 11.78 & 3.87 & 13.16 & 2.48 \\
\hline $55-59$ & 8.19 & 10.82 & 25.81 & 6.93 & 17.94 & 7.17 & 16.9 & 5.81 & 14.87 & 4.42 & 14.41 & 3.72 \\
\hline $60-64$ & 12.21 & 14.27 & 28.41 & 9.87 & 19.18 & 8.04 & 19.28 & 9.37 & 17.48 & 9.14 & 15.58 & 5.13 \\
\hline $65-69$ & 18.92 & 18.33 & 33.04 & 8.75 & 24.72 & 7.9 & 20.51 & 11.89 & 23.69 & 6.81 & 20.91 & 7.46 \\
\hline $70-74$ & 29.45 & 20.88 & 60.57 & 17.79 & 50.2 & 11.21 & 45.09 & 14.64 & 41.35 & 9.63 & 40.26 & 9.59 \\
\hline $75-79$ & 28.01 & 28.27 & 65.77 & 14.46 & 41.1 & 7.23 & 40.4 & 13.75 & 39.77 & 10.23 & 30.47 & 8.33 \\
\hline $80-84$ & 31.42 & 38.82 & 131.53 & 27.99 & 67.15 & 20.77 & 63 & 15.29 & 47.58 & 11.24 & 51.72 & 12.2 \\
\hline+85 & 14.7 & 28.23 & 59.44 & 12.1 & 25.08 & 6.05 & 15.79 & 7.03 & 14.8 & 4.18 & 12.53 & 3.19 \\
\hline
\end{tabular}

demographic information; deletion of the repeated cases would be done separately in each province and finally in all over country by experienced manual reviewers (Figure 1).

\section{Statistical analysis}

Crude (all ages) and age-specific rates per 100,000 person-year for all provinces were calculated. For each province, the average annual age-standardized incidence rate (ASR) per 100,000 person-year was calculated by the direct method using the world standard population. To describe incidence time trends, we carried out joinpoint regression analysis using the software Joinpoint Regression Program, Version 4.1.1.1 October 2014.

The analysis included logarithmic transformation of the rates, standard error, maximum number of one joinpoints, and minimum of six years between zero joinpoints. All other program parameters were set to default values. The aim of the approach is to identify possible joinpoints where a significant change in the trend occurs. In this study 0 joinpiont (Full model) was a significant model. The final model selected was the most parsimonious of these, with the estimated annual percent change (APC) based on the trend within each segment. In describing trends, the terms "significant increase" or "significant decrease" signify that the slope of the trend was statistically significant $(\mathrm{p}<0.05)$. All statistical tests were two sided.

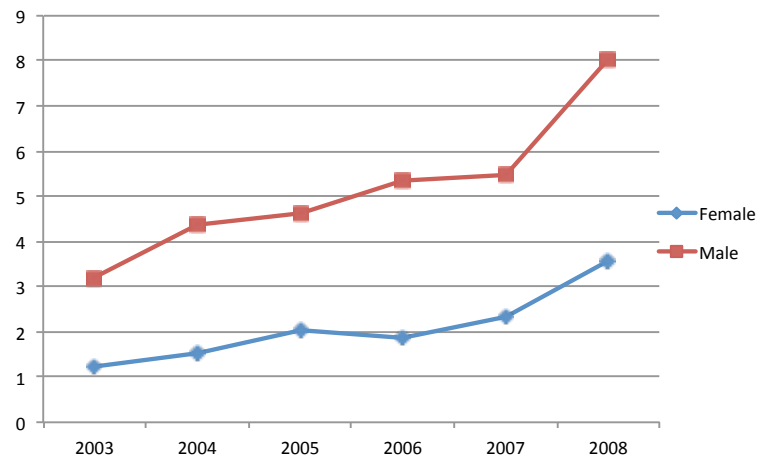

Figure 1. Trend of Lung Cancer Incidence, 2003-2008

\section{Results}

Findings obtained from the national registry system of cancer showed that the incidence of lung cancer had increasing trend from 2003 to 2008 (Figure 1). That is, 11,429 cases of lung cancer have been registered in the country. Of the incidence cases, $8463(74.05 \%)$ cases were male and were female $2966(25.95 \%)$ and sex ratio (male to female) for disease was equal to 2.85 in these years. The highest incidence rate (3050cases) was observed in 2008 , but the lowest rate (963 cases) was recorded in 2003 (Table 1). 
Table 3. Trend of ASR in Iranian Province from 2003 to 2008

\begin{tabular}{|c|c|c|c|c|c|c|c|c|c|c|c|c|c|c|}
\hline \multirow[t]{2}{*}{ Province } & \multicolumn{2}{|c|}{2003} & \multicolumn{2}{|c|}{2004} & \multicolumn{2}{|c|}{2005} & \multicolumn{2}{|c|}{2006} & \multicolumn{2}{|c|}{2007} & \multicolumn{2}{|c|}{2008} & \multicolumn{2}{|c|}{ APC $*(2003-2008)^{*}$} \\
\hline & $\mathrm{M}$ & $\bar{F}$ & M & $\mathrm{F}$ & $\mathrm{M}$ & $\mathrm{F}$ & M & $\mathrm{F}$ & $\mathrm{M}$ & $\mathrm{F}$ & $\mathrm{M}$ & $\mathrm{F}$ & $\mathrm{M}$ & $\bar{F}$ \\
\hline East Azarbaijan & 0.3 & 0.07 & 8.27 & 2.19 & 4.05 & 1.36 & 3.21 & 1.2 & 8.22 & 4.48 & 9.32 & 3.81 & 62.21 & 87.53 \\
\hline West Azarbaijan & 8.76 & 1.89 & 12.83 & 3.18 & 11.76 & 2.86 & 11.18 & 2.85 & 11.78 & 3.02 & 6.76 & 1.67 & 4.48 & -2.2 \\
\hline Ardabil & 0.33 & 0 & 2.35 & 0.49 & 0.64 & 0.24 & 5.35 & 1.87 & 1.68 & 1.64 & 9.23 & 4.1 & 66.16 & $285.97^{\wedge}$ \\
\hline Esfahan & 1.51 & 0.66 & 1.93 & 1.26 & 3.41 & 2.01 & 3.68 & 0.84 & 2.6 & 1.55 & 4.07 & 2.49 & 18.46 & 21.05 \\
\hline Ilam & 1.74 & 0 & 2.59 & 0.32 & 0.43 & 0 & 3.95 & 0.78 & 1.13 & 1.43 & 4.36 & 0.42 & 15.9 & 225.92 \\
\hline Bushehr & 1.16 & 0 & 1.4 & 0.89 & 1.26 & 0.51 & 4.28 & 1.32 & 3.97 & 5.36 & 5.37 & 1.59 & $40.94^{\wedge}$ & 243.54 \\
\hline Tehran & 6.66 & 3.32 & 2.38 & 0.99 & 2.43 & 1.49 & 4.46 & 1.72 & 4.55 & 2.12 & 10.33 & 5.1 & 14.52 & 13.96 \\
\hline \multicolumn{15}{|l|}{ Chaharmahal } \\
\hline \&Bakhtiari & 0.2 & 0 & 0.57 & 1 & 3.26 & 0.82 & 2.97 & 0.43 & 1.86 & 2.17 & 1.65 & 1.64 & 49.21 & 202.06 \\
\hline Khorasan Razavi & 3.53 & 2.05 & 4.02 & 2.46 & 2.24 & 1.35 & 5.56 & 1.66 & 4.57 & 2.02 & 4.47 & 2.91 & 7.33 & 3.98 \\
\hline Khuzestan & 3.4 & 1.49 & 5.71 & 1.29 & 4.65 & 2.01 & 4.56 & 1.66 & 4.18 & 2.2 & 12.98 & 6.93 & 17.83 & 29.68 \\
\hline Zanjan & 0 & 0 & 2.43 & 0.8 & 1.79 & 0.91 & 3.89 & 1.95 & 5.97 & 1.79 & 4.55 & 1.55 & 267.84 & 211.29 \\
\hline Semnan & 0.22 & 0 & 0.74 & 0.5 & 1.19 & 0.38 & 2.71 & 0.52 & 1.24 & 0.84 & 1.23 & 6.3 & $92.13^{\wedge}$ & $268.10^{\wedge}$ \\
\hline \multicolumn{15}{|l|}{ Sistan and } \\
\hline Baluchistan & 0.38 & 0.39 & 0.65 & 0.66 & 1.21 & 0.51 & 0.79 & 0.49 & 1.67 & 0.85 & 0.08 & 0.38 & $36.55^{\wedge}$ & $23.43^{\wedge}$ \\
\hline Fars & 1.26 & 0.31 & 1.45 & 0.47 & 1.91 & 0.95 & 3.1 & 1.33 & 7.29 & 3.58 & 6.64 & 3.57 & $47.65^{\wedge}$ & $70.36^{\wedge}$ \\
\hline Ghazvin & 4.51 & 0.58 & 1.69 & 0.5 & 4.2 & 2.21 & 5.59 & 1.77 & 5.89 & 1.04 & 4.52 & 1.57 & 12.24 & 21.98 \\
\hline Qom & 0 & 0.46 & 3.1 & 1.46 & 3.64 & 2.57 & 5.69 & 2.39 & 6.44 & 1.04 & 5.09 & 2.24 & 265 & 21.53 \\
\hline Golestan & 1.82 & 0.61 & 1.24 & 1.05 & 1.88 & 0.91 & 3.68 & 0.41 & 4.52 & 2.27 & 2.92 & 1.9 & 21.85 & 22.83 \\
\hline Gillan & 2.22 & 0.39 & 3.37 & 0.19 & 3.67 & 1.6 & 5.1 & 1.38 & 6.15 & 1.78 & 8.19 & 1.86 & $28.08^{\wedge}$ & 50.79 \\
\hline Lorestan & 0.96 & 0.37 & 1.17 & 0.66 & 0.55 & 0.24 & 2.09 & 0.5 & 2.35 & 1.74 & 7.04 & 1.72 & 46.6 & 38.21 \\
\hline Mazandara & 2.38 & 0.7 & 3.42 & 1.09 & 5.27 & 1.69 & 3.68 & 1.52 & 3.37 & 1.06 & 7.31 & 2.48 & 16.04 & 19.16 \\
\hline Markazi & 1.09 & 0.37 & 2.12 & 0 & 2.12 & 0.56 & 2.13 & 1.16 & 3.09 & 2.5 & 4.97 & 1.7 & $28.30^{\wedge}$ & 148.25 \\
\hline Hormozgan & 0.2 & 0 & 2.68 & 0.31 & 2.92 & 0 & 2.36 & 0.22 & 1.81 & 0.84 & 3.38 & 0.54 & 76.26 & 212.16 \\
\hline Hamedan & 2.07 & 0.66 & 3.22 & 0.32 & 2.58 & 0.54 & 3.07 & 1.07 & 4.14 & 0.75 & 13.96 & 1.97 & 10.14 & 28.24 \\
\hline Kurdistan & 3.26 & 0.71 & 6.27 & 2.69 & 4.91 & 1.95 & 7.77 & 1.74 & 7.71 & 3.16 & 12.37 & 3.26 & $24.7^{\wedge}$ & 25.76 \\
\hline Kerman & 3.74 & 0.48 & 5.85 & 1.82 & 4.47 & 1.51 & 3.93 & 2.05 & 5.35 & 2.24 & 7.92 & 3.17 & 10.06 & $34.4^{\wedge}$ \\
\hline Kermanshah & 5.4 & 1.67 & 4.44 & 0.66 & 2.64 & 0.65 & 2.18 & 1.13 & 6.33 & 2.28 & 7.93 & 2.18 & 16.21 & 17.37 \\
\hline \multirow{2}{*}{\multicolumn{2}{|c|}{$\begin{array}{l}\text { Kohkilooyeh } \\
\text { and Boyer Ahmad } 0\end{array}$}} & & & & & & & & & & & & & \\
\hline & & 0 & 0.49 & 1.06 & 1.28 & 0.51 & 1.36 & 0.95 & 1.99 & 2.17 & 3.66 & 0.56 & 264.75 & 170.8 \\
\hline Yazd & 5.66 & 2.66 & 5.2 & 0.74 & 5.06 & 2.49 & 8.27 & 2.85 & 5.57 & 1.51 & 9.09 & 6.35 & 9.16 & 20.84 \\
\hline
\end{tabular}

*Annual Percent Change; $\wedge$ APC is significantly different from zero at alpha=0.05; M=Male; F=Female

Table 4. Frequency and Percent Change in the Percentage Allocated to the Morphology Data for Lung Cancer (2008-2003)

\begin{tabular}{lcccrrr}
\hline & $\begin{array}{c}2003 \\
\mathrm{n}(\%)\end{array}$ & $\begin{array}{c}2004 \\
\mathrm{n}(\%)\end{array}$ & $\begin{array}{c}2005 \\
\mathrm{n}(\%)\end{array}$ & $\begin{array}{r}2006 \\
\mathrm{n}(\%)\end{array}$ & $\begin{array}{c}2007 \\
\mathrm{n}(\%)\end{array}$ & $\begin{array}{c}2008 \\
\mathrm{n}(\%)\end{array}$ \\
\hline Female & & & & & & \\
$\quad$ Squamous Cell Carcinoma, Nos & $67(24.19)$ & $93(27.93)$ & $107(22.38)$ & $90(20.45)$ & $97(17.6)$ & $134(16.13)$ \\
Adenocarcinoma, Nos & $58(20.94)$ & $69(20.72)$ & $115(24.06)$ & $109(24.77)$ & $148(26.86)$ & $239(28.76)$ \\
Small Cell Carcinoma, Nos & $51(18.41)$ & $43(12.91)$ & $58(12.13)$ & $58(13.18)$ & $41(7.44)$ & $51(6.14)$ \\
Carcinoma, Nos & $15(5.42)$ & $24(7.21)$ & $33(6.9)$ & $30(6.82)$ & $37(6.72)$ & $58(6.98)$ \\
Bronchiolo-Alveolar Adenocarcinoma & $14(5.05)$ & $18(5.41)$ & $21(4.39)$ & $24(5.45)$ & $35(6.35)$ & $27(3.25)$ \\
Non-Small Cell Carcinoma (C34._) & $0(0)$ & $0(0)$ & $31(6.49)$ & $17(3.86)$ & $28(5.08)$ & $42(5.05)$ \\
Male & & & & & & \\
Squamous Cell Carcinoma, Nos & $362(41.71)$ & $470(40.83)$ & $535(41.6)$ & $510(34.44)$ & $524(34.93)$ & $627(28.56)$ \\
Small Cell Carcinoma, Nos & $121(13.94)$ & $198(17.2)$ & $191(14.85)$ & $212(14.31)$ & $226(15.07)$ & $255(11.62)$ \\
Adenocarcinoma, Nos & $111(12.79)$ & $160(13.9)$ & $168(13.06)$ & $217(14.65)$ & $203(13.53)$ & $402(18.31)$ \\
Carcinoma, Nos & $49(5.65)$ & $41(3.56)$ & $45(3.5)$ & $95(6.41)$ & $74(4.93)$ & $131(5.97)$ \\
Bronchiolo-Alveolar Adenocarcinoma & $21(2.42)$ & $28(2.43)$ & $37(2.88)$ & $38(2.57)$ & $33(2.2)$ & $43(1.96)$ \\
Non-Small Cell Carcinoma (C34._) & $0(0)$ & $0(0)$ & $80(6.22)$ & $74(5)$ & $99(6.6)$ & $107(4.87)$ \\
\hline
\end{tabular}

The age-specific rate in men increased from 3.2 in 2003 to 8.04 in 2008. The highest and lowest incidence rate in men observed in 2008 and 2003, respectively. In women, this rate also elevated from 1.23 in 2003 to 3.55 in 2008 per 100,000 people. The maximum and minimum incidence rates were 3.55 and 1.23 per 100,000 people, respectively in 2008 and 2003. Furthermore, in women and men trend of Lung cancer incidence was increasing.
The highest and lowest sex ratios were 3.39 and 2.63, respectively in 2004 and 2008 (Table 1 and Figure 1). Joinpoint Trend Analysis showed a significant increase for age-standardized incidence rate (ASR) for both sexes. The annual percentage change (APC) of standardized incidence rate for females and males were $20.5 \%$ (CI: 10.8 to 31.1 ) and $16.7 \%$ (CI: 9 to 24.9), respectively.

In this study, the age-specific rate was different in age 
groups so that as age rises, the incidence of Lung cancer in men and women was increased, and the highest rate was observed at 80-84 years but it decreased at above 85 years. Furthermore, the age-specific rate in overall has rising trends from 2003 to 2008 (Table 2).

In 2008, the age-specific rate of Lung cancer was highest in males in Hamedan, Semnan, and Khuzestan provinces (13.96, 13.23, and 12.98, respectively). The highest ASRs were seen in females in Khuzestan, Yazd, and Semnan provinces (6.93, 6.35, and 6.30, respectively). The lowest ASR in male was observed in Zanjan and Kohkilooyeh and Boyer Ahmad, and in female in Ardabil, Bushehr, chaharmahal \& bakhtiari, Zanjan, Semnan, Kohkilooyeh and Boyer Ahmad, Hormozgan and Ilam provinces. Joinpoint analysis and gender segregation in the trend of both sexes for all provinces except the Western Azerbaijan province was increased. For three provinces of Semnan, Sistan-Baluchestan and Fars increased for both genders was significant (P-Value $<0.05)$. Based on annual percentage changes (APC), highest and lowest significant increase respectively for women Ardebil (285.97\%) and women in Sistan-Baluchestan (285.97\%), respectively. Annual percentage changes (APC), for West Azerbaijan province showed a decreasing trend [Table 3].

During the study years, allocated percentages for histology types were different. Squamous Cell Carcinoma Nos, Adenocarcinoma Nos, Small Cell Carcinoma Nos, Carcinoma Nos, Non-Small Cell Carcinoma and Bronchiolo-Alveolar Adenocarcinoma in two gender have a rising trend in study duration, so in male Squamous Cell Carcinoma Nos has maximum rising in annually incidence and minimum Bronchiolo-Alveolar Adenocarcinoma and in female Adenocarcinoma Nos has maximum rising in annually incidence and minimum in bronchiolo-alveolar adenocarcinoma [Table 4].

\section{Discussion}

The findings indicated that the incidence of Lung cancer was increasing. The increase in men than women. The trend was observed in all provinces. The highest incidence rate of Lung cancer was in males in Hamedan, Semnan, and Khuzestan provinces. The highest incidence rates were seen in females in in Khuzestan, Yazd, and Semnan provinces. The lowest ASR in male was observed in Zanjan and Kohkilooyeh and Boyer Ahmad, and in female in Ardabil, Bushehr, chaharmahal and bakhtiari, Zanjan, Semnan, Kohkilooyeh and Boyer Ahmad, Hormozgan and Ilam provinces. The incidence of the disease was more in all provinces in men than women. There was a direct association between Lung cancer and age so that the incidence of Lung cancer was increased as age rises. Other studies also confirmed the increasing trend of the Lung cancer (Sadjadi et al., 2003; Mehrabani et al., 2008; Somi et al., 2008; Babaei et al., 2009; Koosha et al., 2011; Hshyany et al., 2012).

The results of this study showed that, during the period 2003 through 2008, the trend of Lung cancer incidence in Iran was increasing; the low incidence rate of cancer in 2003 was not due to the fact that few cancer cases occurred, but rather owing to the incomplete registration of cancer cases at the beginning of the cancer registry program. Iranian national reports of cancer registry showed that the average annual percentage change for standardized incidence rate in all cancer was $9.6 \%$ in males and 10.6\% in females during 2003-2008 (Goya, 2007). Despite the increasing trend of lung cancer in Iran, studies carried out in America (Wahbah et al., 2007) show the decreasing trend in the incidence of this cancer. In another study in Europe showed that the incidence of lung cancer in men in Denmark, Finland, Germany, Italy, Netherlands, Switzerland and the United Kingdom since the 1980s has decreased, but it is in other European countries has increased at least to the 1990s (Janssen-Heijnen and Coebergh, 2003). Also in the study between the years 2000-1983 in Hong Kong showed that the incidence of lung cancer in men and women in this country has decreased (Au et al., 2004).

Lung cancer was an occupational disease (Du et al., 1996; Kabat, 1996; Chan-Yeung et al., 2003) and the main risk factors for this disease is Smoking. The prevalence of smoking in men more than women (Wang et al., 1996). The expected incidence of this disease is higher in men than women. The study also it was observed that in all the years under study, the incidence in men than women. Epidemiological studies indicate that some characteristics of lung cancer among smokers significantly differ from those of unmakes. Carcinogens found in cigarettes, risk of developing of primary lung carcinoma increases, So that $85 \%$ of patients with any histologic type of lung cancer, a history of smoking (previous or current) would have had. The relative risk of this cancer by smoking, about 13 equal and in case of Long term exposure to inactive also increased 1.5 equal. In addition, exposure to some of the industrial substances, including arsenic, asbestos, chromium, susceptibility to chronic lung disease and history of previous tuberculosis with secondary scarring, the increased risk of primary lung carcinoma are effective (; Alberg, 2007; Toh, 2009).

The incidence of Lung cancer is increasing in the country, especially in the Northwest Territories and the West is increasing, therefore etiology and diagnostic programs in the country, especially in these areas is essential,And suggested that the cause of cognitive studies done in these areas. Our findings were obtained from the descriptive study on the incidence trend of the disease in recent years and it is recommended that analytical studies should be conducted to obtain a causal relationship and solve problems related to the disease.

\section{Acknowledgements}

Hereby we appreciate of the cooperation of all employees involved in data collection in the country, especially in NCR, and CDC of the Ministry of Health and Medical Education.

\section{References}

Alberg A, Ford J, Samet J (2007). Epidemiology of lung cancer. ACCP evidence-based clinical practice guidelines $\left(2^{\text {nd }} \mathrm{ed}\right)$, 132(3 Suppl), 29-55. 
Au J, Mang O, Foo W, et al (2004). Time trends of lung cancer incidence by histologic types and smoking prevalence in Hong Kong 1983-2000. Lung Cancer, 45, 143-52.

Babaei M, Jaafarzadeh H, Sadjadi A, et al (2009). Cancer Incidence and Mortality in Ardabil: Report of an Ongoing Population-Based Cancer Registry in Iran, 2004-2006. Iranian J Publ Health, 38, 35-45.

Bosetti C, Bertuccio P, Levi F, et al (2008). Cancer mortality in the European Union, 1970-2003, with a joinpoint analysis. Ann Oncol, 19, 631-40.

Chan-Yeung M, Koo L, Ho J, et al (2003). Risk factors associated with lung cancer in Hong Kong. Lung Cancer, 40, 131-40.

Cruz CD, Tanoue L, Matthay R (2011). Lung cancer: epidemiology, etiology, and prevention. Clin Chest Med, 32, 605-44.

Du YX, Cha Q, Chen XW, et al (1996). An epidemiological study of risk factors for lung cancer in Guangzhou, China. Lung Cancer, 14, 9-37.

Fauci, Anthony S (2008). Harrison's principles of internal medicine, McGraw-Hill Medical New York.

Ferlay J, Shin H, Bray F, et al (2010). Estimates of worldwide burden of cancer in 2008: GLOBOCAN 2008. Int J Cancer, 127, 2893-917.

Ferlay J, Shin H, Bray F, et al (2010). GLOBOCAN 2008, cancer incidence and mortality worldwide, Lyon, France, IARC cancerbase no. 10.

Goya MM (2007). Iranian annual cancer registration report 2003/2008, tehran, ministry of health and medical education, health deputy. Center for Disease Control and Prevention.

Hadoux J, Besse B, Planchard D (2011). Lung cancer in never smoker: Epidemiology, molecular profiles and treatment. Presse Med, 40, 371-8.

Horner M, Ries L, Krapcho M (2009). SEER Cancer [Online]. Bethesda, MD: Based on November 2008 SEER submission data, posted to the SEER website.

Hosseini M, Naghan P, Karimi S, et al ( (2009). Environmental risk factors for lung cancer in Iran: a case-control study. Int $J$ Epidemiol, 38, 989-96.

Hshyany AA, Farahmand M, Hasanzadeh J, et al (2012). The incidence of lung cancer in the province based on cancer registry data 2001-8. Payesh, 11, $483-77$.

$\mathrm{Hu} \mathrm{Z}$, Wu C, Shi Y, et al (2011). A genome-wide association study identifies two new lung cancer susceptibility loci at 13q12.12 and 22q12.2 in Han Chinese. Nat Genet, 43, 792-6.

Hussain S, Hofseth L, Harris C (2001). Tumor suppressor genes: at the crossroads of molecular carcinogenesis, molecular epidemiology and human risk assessment. Lung Cancer, 34, 7-15.

Janssen-Heijnen M, Coebergh J (2003). The changing epidemiology of lung cancer in Europe. Lung Cancer, 41, 245-58.

Jemal A, Bray F, Center M, et al (2011). Global cancer statistics. CA Cancer J Clin, 61, 69-90.

Jiao Z, Hai-Tao W, Bao-Guo L (2014). Prognostic Significance of Circulating Tumor Cells in Small-Cell Lung Cancer Patients: a Meta-analysis. Asian Pac J Cancer Prev, 15, 8429-33.

Kabat G (1996). Aspects of the epidemiology of lung cancer in smokers and nonsmokers in the United States. Lung Cancer 15, 1-20.

Kazemi-Lomedasht F, Rami A,Zarghami N (2013). Comparison of inhibitory effect of curcumin nanoparticles and free curcumin in human telomerase reverse transcriptase gene expression in breast cancer. Adv Pharm Bull, 3, 127-30.

Keyghobadi N, Rafiemanesh H, Hafshejani AM, et al (2015). Epidemiology and trend of cancers in the province of Kerman: Southeast of Iran. Asian Pac J Cancer Prev, 16, 1409-13.
Khajehkazemi R, Sadeghirad B, Karamouzian M (2013). The projection of burden of disease in Islamic Republic of Iran to 2025. PloS ONE, 8, 76881 .

Koohi F, Enayatrad M, Salehiniya H (2015). A Study of the Epidemiology and Trends in Cancer Incidence in Iranian Elderly 2003-2009. Arak Med University J, 18, 57-66.

Koosha A, Farahbakhsh M, Hakimi S, et al (2011). Epidemiology of Cancer in East Azerbaijan province in 2008. Tabriz University Med Sci, 32, 74-9.

Li Y, Sheu C, Ye Y, et al (2010). Genetic variants and risk of lung cancer in never smokers: a genome-wide association study. Lancet Oncol, 11, 321-30.

Mehrabani D, Tabei S, Heydari S, et al (2008). Cancer Occurrence in Fars Province, Southern Iran. Iranian Red Crescent Med J, 10, 314-22.

Miki D, Kubo M, Takahashi A, et al (2010). Variation in TP63 is associated with lung adenocarcinoma susceptibility in Japanese and Korean populations. Nat Genet, 42, 893-6.

Ming Z, Cui-Huan W, Xiao-Ling Z, et al (2014). Loss of imprinting of insulin-like growth factor 2 is associated with increased risk of primary lung cancer in the central china region. Asian Pac J Cancer Prev, 15, 7799-803.

Molina J, Yang P, Cassivi S, et al (2008). Non-small cell lung cancer: epidemiology, risk factors, treatment, and survivorship. Mayo Clin Proc, 83, 584-94.

Organization WH (2011). WHO report on the global tobacco epidemic, 2011, warning about the dangers of tobacco. , Geneva, Switzerland, WHO press, 2011.

Parkin DM, Bray F, Ferlay J, et al (2005). Global cancer statistics, 2002. CA Cancer J Clin, 55, 74-108.

Sadjadi A, Malekzadeh R, Derakhshan M, et al (2003). Cancer occurrence in Ardabil: Results of a population based Cancer Registry from Iran. Int J Cancer, 107, 113-8.

Seyed Mohsen Mousavi, Gouya MM, Ramazani R, et al (2009). Cancer incidence and mortality in Iran. Ann Oncol, 20, 556-63.

Shiraishi K, Kunitoh H, Daigo Y, et al (2012). A genome-wide association study identifies two new susceptibility loci for lung adenocarcinoma in the Japanese population. Nat Genet, 44, 900-3.

Siegel R, Naishadham D, Jemal A (2013). Cancer statistics 2013. CA Cancer J Clin, 63, 11-30.

Somi M, Farhang S, Mirinezhad S, et al ( 2008). Cancer in East Azerbaijan, Iran: results of a population-based cancer registry. Asian Pac J Cancer Prev, 9(2), 327-30.

Toh C-K ( 2009). The changing epidemiology of lung cancer. Methods Mol Biol, 472, 397-411.

Toh C, Lim W (2007). Lung cancer in never-smokers. J Clin Pathol, 60, 337-40.

Wahbah M, Boroumand N, Castro C, et al (2007). Changing trends in the distribution of the histologic types of lung cancer: a review of 4439 cases. Ann Diagn Pathol, 11, 89-96.

Wang SY, Hu Yl, Wu Yl, et al (1996). A comparative study of the risk factors for lung cancer in Guangdong, China. Lung Cancer, 14, 99-105.

Wang Y, Broderick P, Webb E, et al (2008). Common 5p15.33 and 6 p21.33 variants influence lung cancer risk. Nat Genet, 40, 1407-9. 